\title{
Revision of constitutive models for repairing bridge columns with fiber polymers
}

\author{
H. Hernández ${ }^{1}$, J.M. Jara ${ }^{1} *$ M. Jara ${ }^{1}$ \\ ${ }^{1 *}$ Civil Engineering School, Universidad Michoacana de San Nicolás de Hidalgo,Morelia, Michoacán, MÉXICO \\ "Corresponding Author: e-mail: jmjara70@gmail.com
}

\begin{abstract}
Federal Highway Network in Mexico has 7,230 bridges. More than two third parts were built in the period of 1960 to 1970 without considering in their design seismic loads or using design spectra with small amplitudes. The use of Fiber Reinforced Polymers (FRP) is a plausible alternative for retrofitting columns that have suffered some type of damage during a seismic event. In this paper, models of confinement with purpose of application in repairing damage of circular columns of bridges are analyzed. When evaluating different expressions for the confinement thickness of FRP in columns, a great dispersion exists. Each author of the revised models endorses analytically and experimentally its results, but for practical applications it is difficult to determine the appropriate model to be used.
\end{abstract}

Keywords: Repair, Bridges, Columns, Fiber Polymers.

\section{Introduction}

There is no doubt that the infrastructure, particularly for transportation, constitutes an essential element for economic growth, competitiveness and social integration of a country. In Mexico, the free toll Federal Highway Network has a longitude of 45,405.7 $\mathrm{km}$ with 7,230 bridges of which more than two third parts were built in the period of 1960 to 1970. In case of strong seismic event, it is necessary to carry out a prompt bridge repairs with the aim of guaranteeing the correct operation of the highway network. At present, it is well-known the effectiveness of the casing of concrete elements with Fiber Reinforced Polymers (FRP) as a seismic reinforcement alternative. However, its applicability for retrofitting bridge damaged columns after a seismic occurrence is currently under study in several parts of the world.

Currently bridge design recommendations suggest the use of the "non-collapse" criteria for the design earthquake. A non-linear bridge response is allowed, conducting to a great deal of damage, including cracking and detachment of the concrete, yielding of the steel reinforcement, and the possibility of rupture of the reinforcement bars. Therefore, after the occurrence of a seismic event a bridge column could be damaged but it would be theoretically repairable. The visual classification of the damage suffered by a column is the first step of the repair process; such classification provides the reference point for determining the condition of the column and the selection of the more appropriate repair technique.

\section{Damage states}

In the Concrete Repair Manual [ACI-440.2R Committee (2002)] there is a procedure to perform a visual inspection of the damage and the actual states of the damage. There are five states in such document (Damage States, DS) namely: DS-1 through DS-5. Damage state DS-1 corresponds to very slight damage with minimum cracking, characterized by the formation of cracks by bending and no visible spalling. Damage state DS-2 has slight damage and occurs when first spalling and shear cracks are visible. Damage state DS-3 is a moderate damage and is associated with extensive cracks and spalling. Damage state DS-4 is represented by a severe damage, in which the spiral and longitudinal reinforcing bars become visible and large cracks, holes and spalled areas are observed. Damage state DS-5 corresponds to very severe damage and is associated with imminent failure and cracks 
propagation inside the concrete core. Table 1 describes the characteristics of each aforementioned damage state as referenced in the Concrete Repair Manual [ACI, BRE (2001)]. In general, two parameters are considered to determine the possibility for a column to be repaired: (1) the deformations of the longitudinal reinforcement and (2) the deformations of the spiral hoop reinforcing bars. Strain quantification in the reinforcing bars is important for determining possible repair methods, i.e. if the longitudinal bars reach a rupture strain, repair via FRP jackets is not appropriated. Likewise, if the spiral hoops reach the yielding strain, damage to the cover core is expected. In this case, repairing with an FRP jacket is not appropriate.

Table 1. Visual Characterization of the Damage State

\begin{tabular}{|c|c|c|c|c|c|}
\hline \multirow{2}{*}{ Damage } & \multicolumn{5}{|c|}{ Damage State } \\
\cline { 2 - 6 } & $\begin{array}{c}\mathbf{1} \\
\text { (Very slight) }\end{array}$ & $\begin{array}{c}\mathbf{2} \\
\text { (Slight) }\end{array}$ & $\begin{array}{c}\mathbf{3} \\
\text { (Moderate) }\end{array}$ & $\begin{array}{c}\mathbf{4} \\
\text { (Severe) }\end{array}$ & $\begin{array}{c}\mathbf{5} \\
\text { (Very severe) }\end{array}$ \\
\hline $\begin{array}{c}\text { Crackswidth on } \\
\text { concrete }\end{array}$ & $<0.10 \mathrm{~mm}$ & $0.10-0.30 \mathrm{~mm}$ & $0.30-1.0 \mathrm{~mm}$ & $1.0-3-0 \mathrm{~mm}$ & $>5 \mathrm{~mm}$ \\
\hline Cavities & Slightly visible & Visible & $\begin{array}{c}\text { Holes with a } \\
\text { diameter of } \\
10 \mathrm{~mm}\end{array}$ & $\begin{array}{c}\text { Holes with a } \\
\text { diameter of } 10- \\
50 \mathrm{~mm}\end{array}$ & $\begin{array}{c}\text { Holes with } \\
\text { diameter } \\
\text { greater than } \\
50 \mathrm{~mm}\end{array}$ \\
\hline $\begin{array}{c}\text { Detachment of } \\
\text { the concrete } \\
\text { cover }\end{array}$ & Slightly visible & Visible & $\begin{array}{c}\text { Greater than } \\
\text { aggregate's } \\
\text { size }\end{array}$ & $\begin{array}{c}\text { In areas greater } \\
\text { than 150mm of } \\
\text { cross-cut } \\
\text { section }\end{array}$ & $\begin{array}{c}\text { In areas greater } \\
\text { than 150mm of } \\
\text { cross-cut } \\
\text { section }\end{array}$ \\
\hline
\end{tabular}

The strain levels in the reinforcement bars can be estimated based on the visual classifications associated with each damage state. It is expected that the longitudinal reinforcing bars yield once flexural cracks are visible, corresponding to DS-1. The longitudinal bars yield at this point because a plastic hinge is formed. Similarly, the spiral reinforcing bars would be expected to yield once the cracks in the concrete propagate into the column core, which corresponds to DS-5. Once the spiral reinforcement yields, FRP jacket repair in not effective. Table 2 shows a relationship between the levels of deformation in the reinforcement steel and the corresponding damage state; it also determines whether it is viable to perform repairs via FRP bands.

Table 2. Parameters of the damage response in relation to the damage state

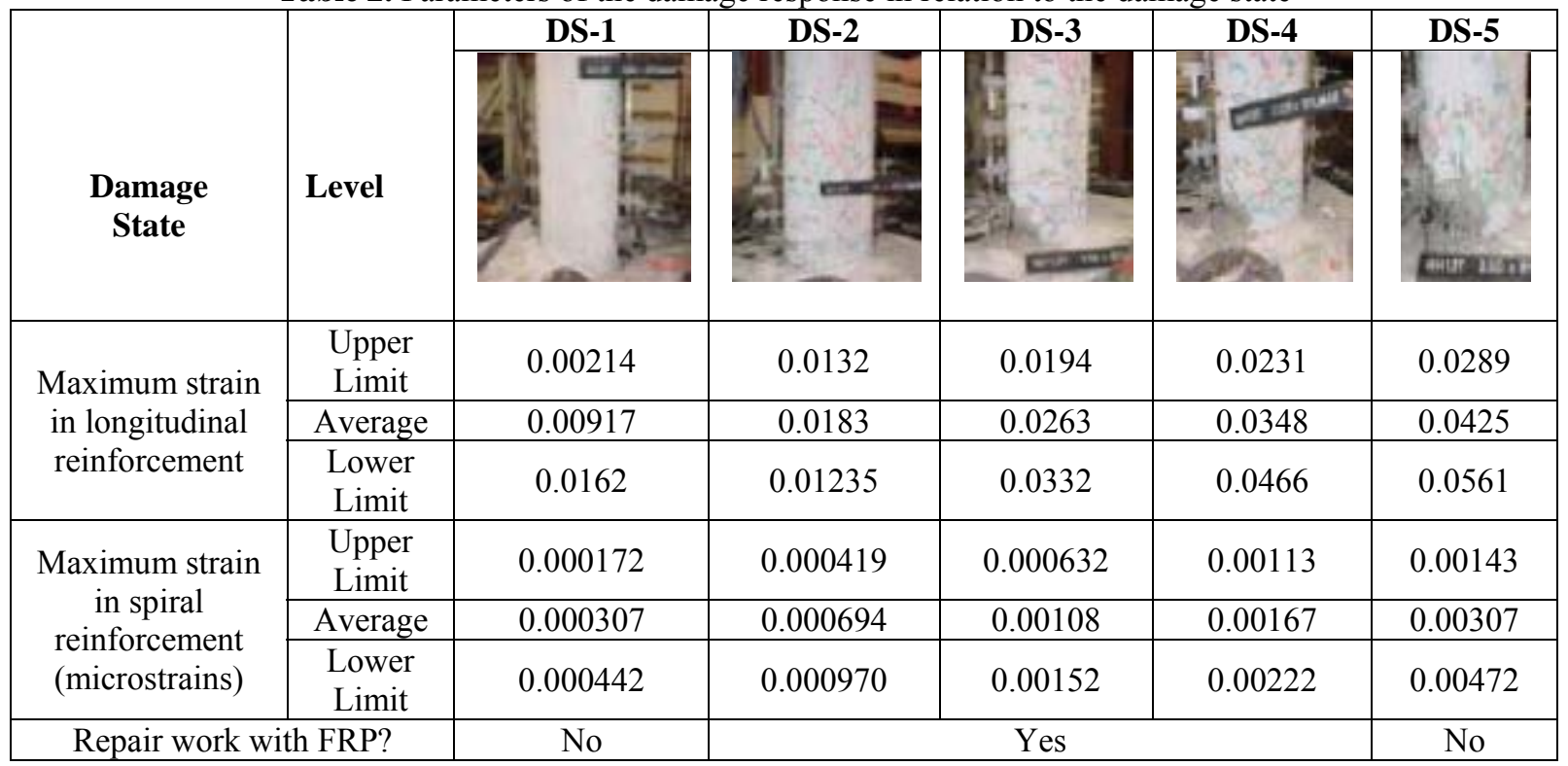

\section{Confinement models for circular columns}

It is well known that the restraint provided by an external jacket, which restricts the transverse dilation of the column, produces some confinement and increases the strength and deformation capacity of the element. Even though a reliable and accurate model of concrete confinement is not yet fully accepted by the researcher's community. Many models of confined strength of concrete and associated strain have been proposed dating back to Richart et al. (1928). Fardis and Khalili (1982) suggested that Richart et al. model could be directly used for FRP confined concrete. However, recent studies revealed that existing models for the axial 
compressive strength of steel confined concrete are unconservative and cannot be used for FRP confined concrete [Teng et al. (2002)]. For a circular column, the lateral confining pressure of the FRP jacket, $f_{l}$, can be evaluated by the free-body diagram shown in Figure 1.

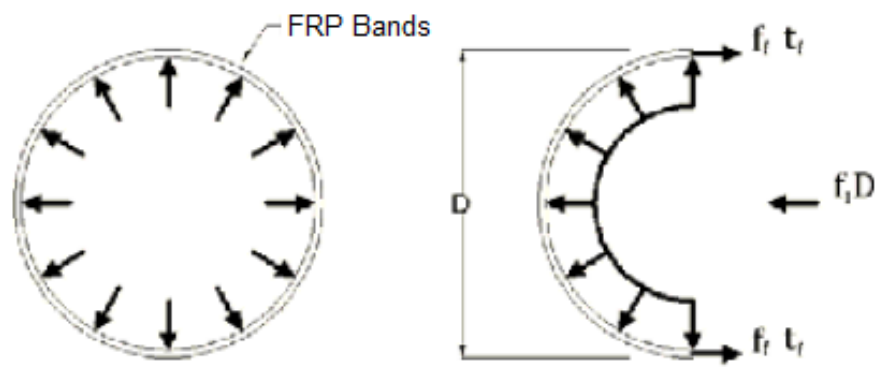

Figure 1. Free-body diagram to calculate the confinement forces

From Figure 1 the following equation is used to calculate the side confinement pressure provided by the FRP bands $f_{l}$,

$$
f_{l}=\frac{2 t_{f} f_{f}}{D}=\frac{2 t_{f} E_{f} \varepsilon_{f}}{D} .
$$

where $t_{f}$ is the thickness of the reinforcement FRP bands, $f_{f}$ is the tension stress of the FRP bands in the radial direction and $D$ is the diameter of the concrete confined section; $E_{f}$ and $\varepsilon_{f}$ are the elastic module and the unitary deformation of the FRP bands in the radial direction, respectively. Because the FRP behaves elastically up to rupture, the pressure held by the reinforcement bands is proportionally increased, in contrast with steel strands that provides a constant side confinement pressure.

In existing reinforced concrete columns with insufficient transversal reinforcement and/or poor seismic detailing, three different types of failure modes can be observed under seismic excitation namely: shear failure mechanism, plastic hinge formation and insufficient development length (Fig. 2). The first and most critical failure mode is the shear failure, where inclined cracking, cover concrete spalling, and rupture or opening of the transverse reinforcement can lead to brittle or explosive column failures. The failure sequence consists of 5 steps, namely: (1) the development of inclined cracks once the tensile strength of the concrete is exceeded, (2) the opening of inclined or diagonal cracks in the column and onset of cover concrete spalling; (3) rupture or opening of the transverse or horizontal reinforcement; (4) buckling of the longitudinal column reinforcement, and (5) disintegration of the column concrete core.
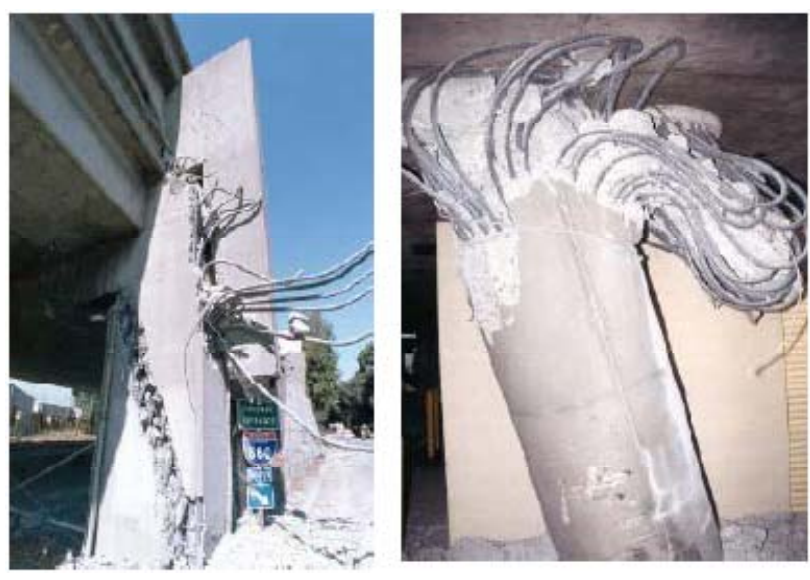

Formation of plastic hinge

Shear failure mechanism

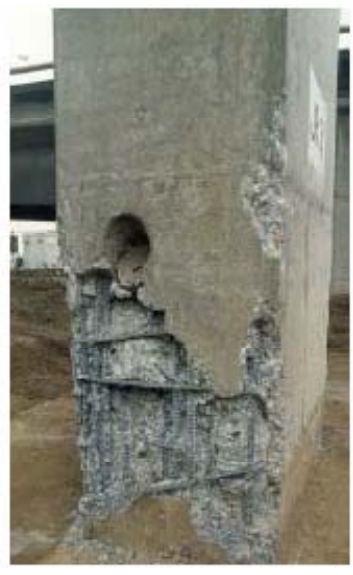

Insufficient development length

Figure 2. Common failures in columns that occurred in 1989 during the Loma Prieta Earthquake

The purpose of the seismic repair work is to improve the seismic performance of the columns by increasing their ductility and their resistance to flexural, shear and axial stresses. An FRP jacket provides confinement increasing the bending stress capacity, the concrete's ultimate strain and providing lateral support. The jacket with FRP bands may contribute to the shear stress capacity of the column and thus inhibit this type of failure. Jacket with FRP bands in columns inhibits the failure for lack of overlapping through the application of confinement pressure on the zone where the failure may occur. It increases the confinement side force and prevents the detachment of the concrete. The failure mode for lateral buckling of the longitudinal reinforcement is considered 
an uncommon mode of failure as a consequence of the close stirrup spacing recommended in many design codes. In literature there are several diverse confinement models for reinforced concrete circular columns with FRP jacket. Hernandez et al. (2009) summarized expressions of 20 different types of confinement models and described the experimental tests conducted by several authors. Such models are expressed in function of stresses (Table 3) or ultimate strains (Table 4).

Table 3. Summary of confinement models based on stresses [Hernández, et al. (2009)]

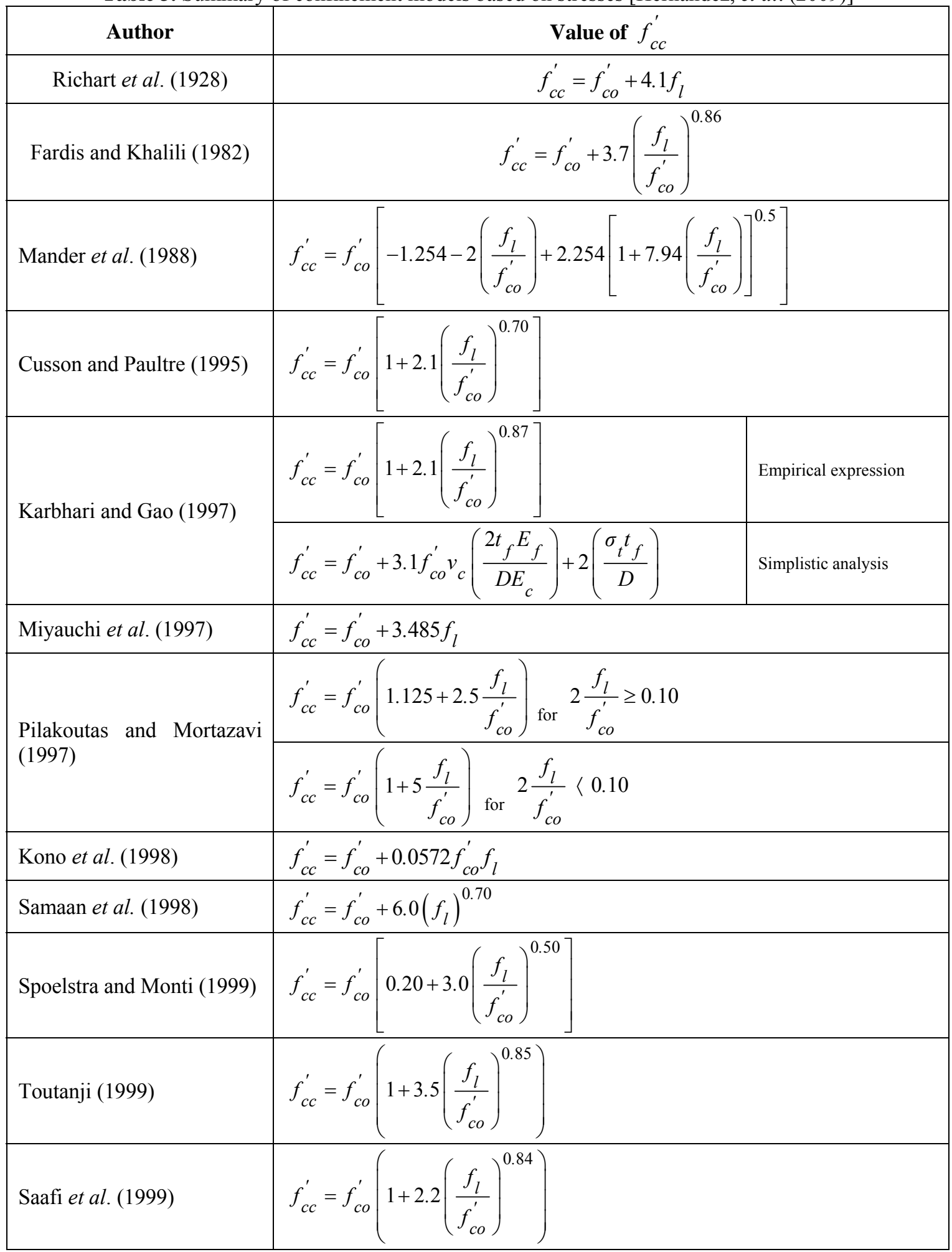

Table 3. Summary of confinement models based on stresses (Continued). 


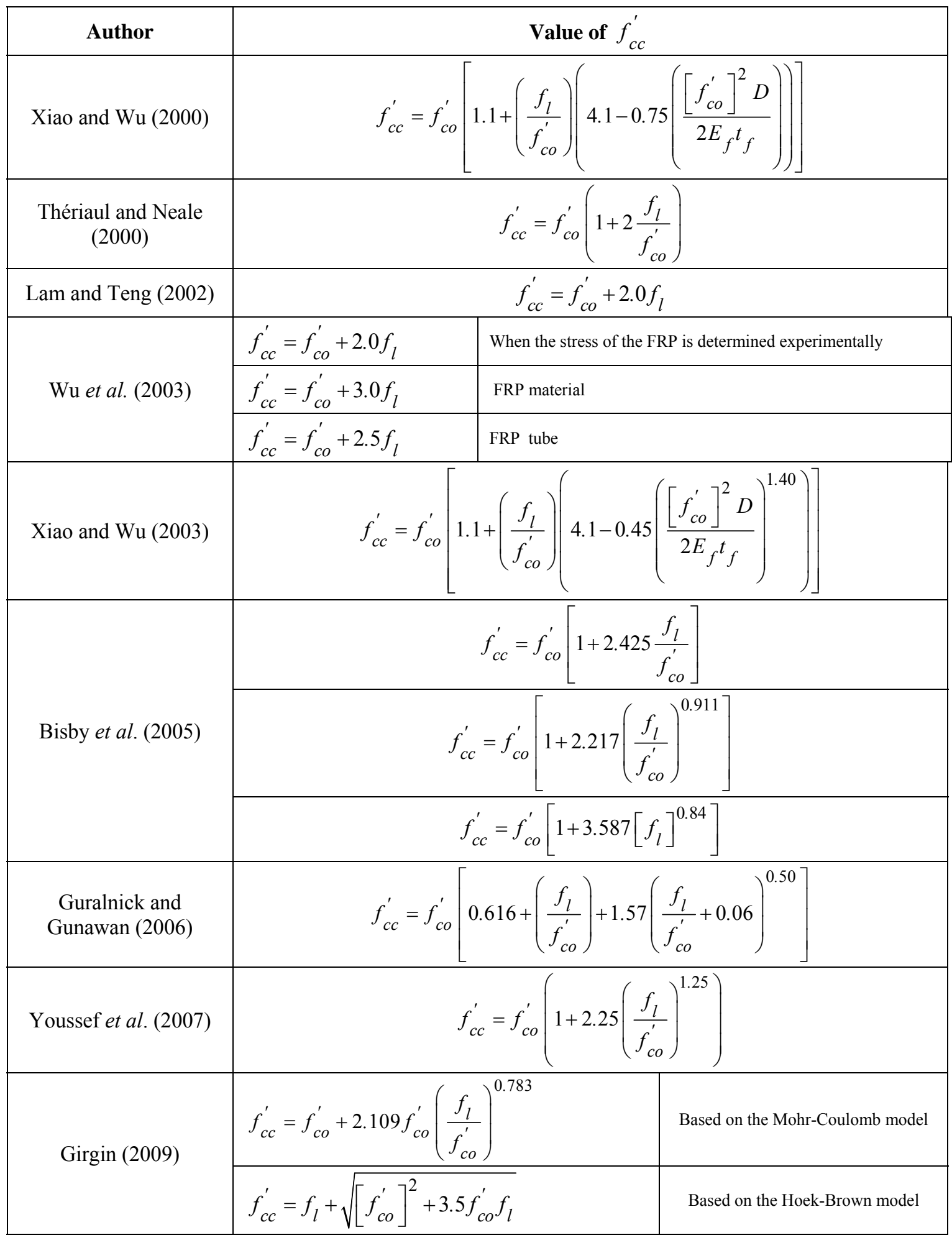

Where $f_{c c}^{\prime}$ is the strength of confined concrete at failure; $f_{l}$ is the lateral confining pressure; $f_{c o}^{\prime}$ is the strength of the unconfined concrete; $\varepsilon_{c c}$ is the strain corresponding to the confined strength; $\varepsilon_{c o}$ is the longitudinal strain of the unconfined concrete at failure, which is typically assumed to be $0.002 ; E_{f}$ is the modulus of elasticity of the FRP jacket; $v$ is the Poisson's ratio; $\varepsilon_{f}$ is the strain in the FRP jacket; $E_{e f f}$ is the effective modulus of elasticity of the FRP in the hoop direction; $E_{c}$ is the modulus of elasticity of the concrete; $t_{f}$ is the thickness of the FRP band and $D$ is the column diameter. 
Table 4. Confinement models based on ultimate strain [Hernández, et al. (2009)]

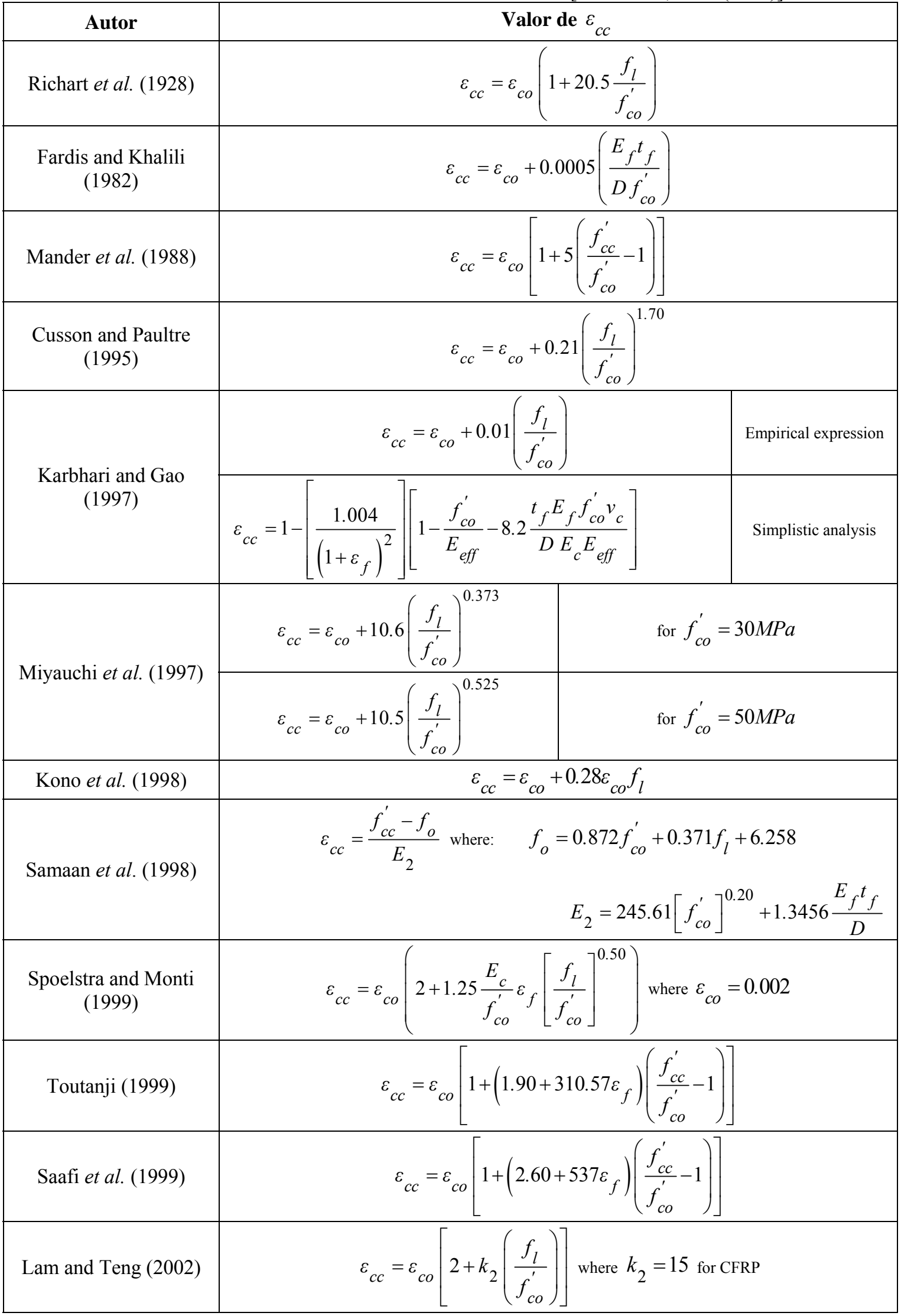


Table 4. Confinement models based on ultimate strain (Continued)

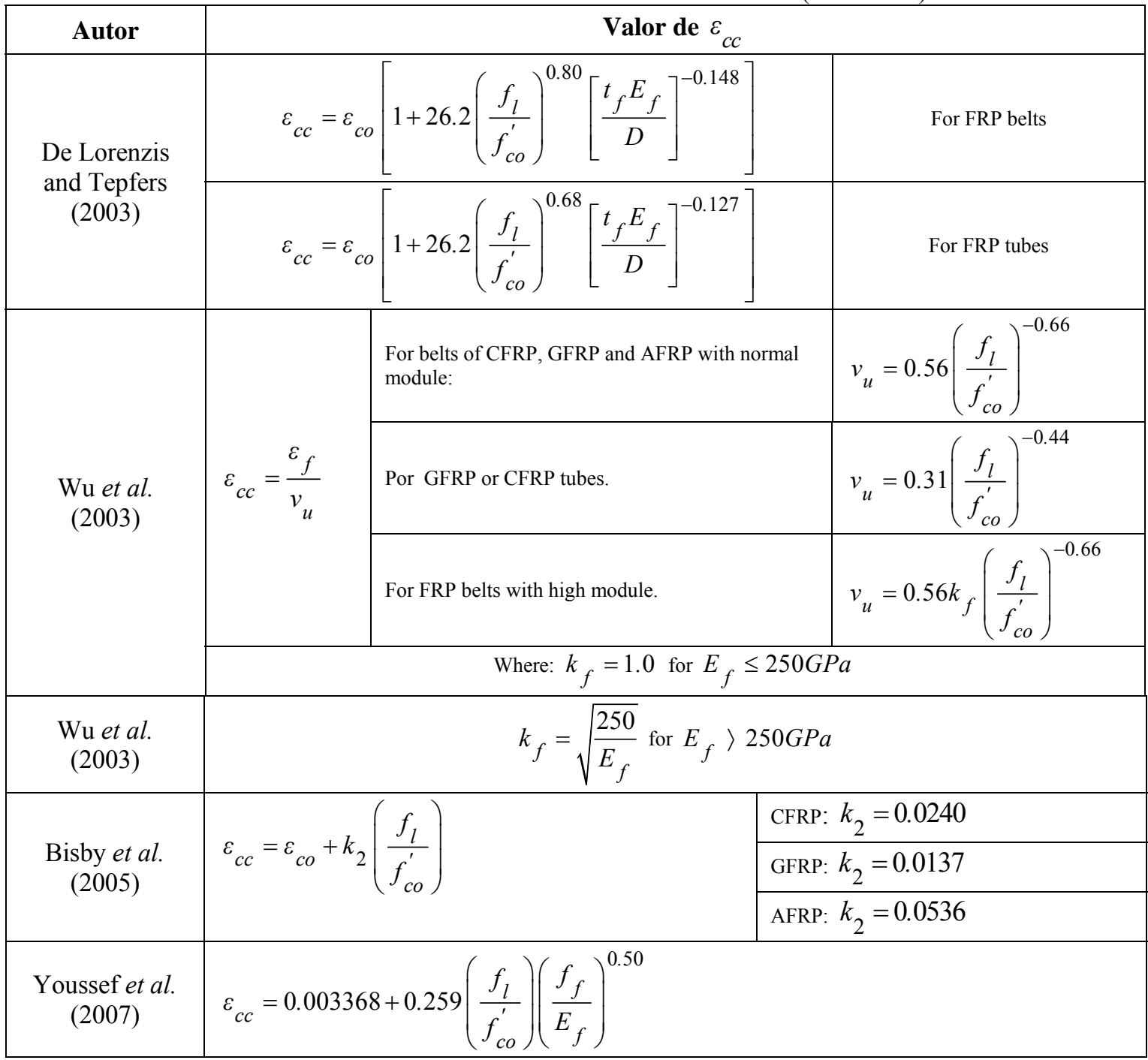

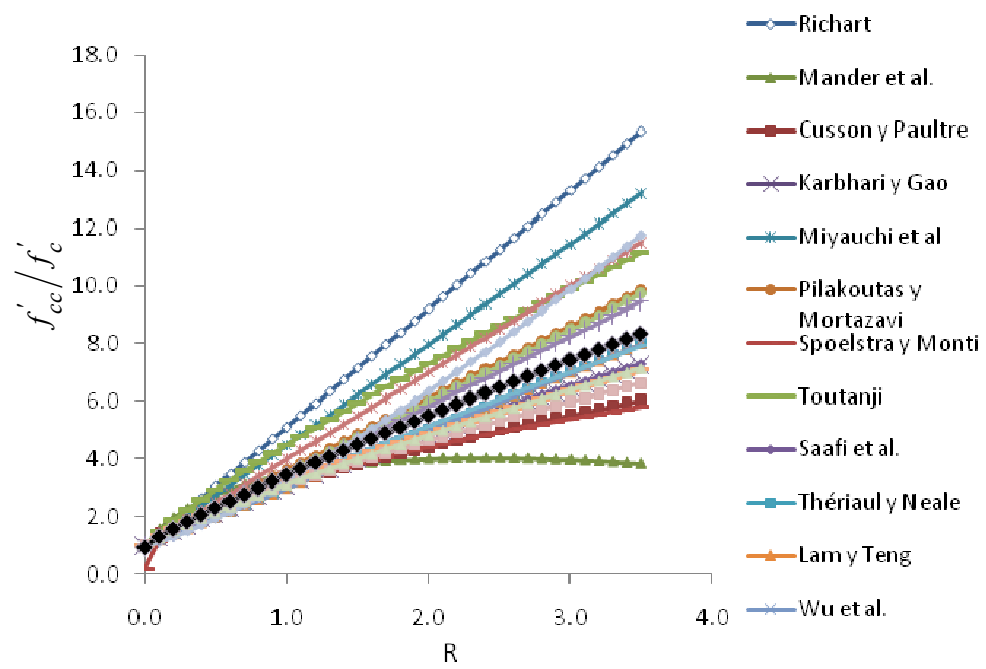

Figure 4. Volumetric relationship R for different confinement models. 
With the purpose of determining the model that can be employed in a fast repair work of bridge columns after an earthquake occurrence, the existing models in the literature are displayed in figure 4. A great dispersion dispersion of the confined sgtrength were obtained for different confinement models as function of the volumetric relationship, $R=f_{l} / f_{c o}^{\prime}$. All authors justify their proposed expressions by the use of experimentally and analytically models. However, Figure 4 shows the large variations among them. The International Federation for Structural Concrete [FIB (2003)] recommends the use of confinement model proposed bySpoelstra and Monti (1999) due to its simplicity and accuracy.

\section{ACI 440.2 R-02 Recommendations (2002)}

The ACI 440.2R-02 (2002) guideline makes use of the confinement model originally proposed by Mander et al. (1988), derived for steel hoop reinforcement. The Mander's confinement model is slightly modified to account for the linearly elastic behavior of FRP. The confinement model predicts the confined strength of concrete, $f_{c c}^{\prime}$, through the following relation:

$$
f_{c c}^{\prime}=f_{c o}^{\prime}\left[2.25 \sqrt{1+7.9 \frac{f_{l}}{f_{c o}^{\prime}}}-2 \frac{f_{l}}{f_{c o}^{\prime}}-1.25\right]
$$

Where $f_{c o}^{\prime}$ is the unconfined concrete strength and $f_{l}$ is the confining pressure, which is defined as follows:

$$
f_{l}=\frac{k_{s} \rho_{f} \varepsilon_{f} E_{f}}{2} .
$$

$k_{S}$ is the efficiency coefficient, which depends on the column geometry. For a circular column, $k_{S}=1.0 ; \varepsilon_{f}$ is defined as the smaller value of 0.0004 or $0.75 \varepsilon_{f u}$, where $\varepsilon_{f u}$ is the ultimate strain in the FRP. This strain limit was chosen to avoid the aggregate interlock loss in the concrete and was determined trough pure axial tests. It is, therefore, an approximation for combined axial and bending situations induced by seismic forces. The volumetric relationship of the FRP is equal to:

$$
\rho_{f}=\frac{4 t_{f}}{D}
$$

Equation (3) can also be written as:

$$
f_{l}=\frac{2 k_{s} t_{f} \varepsilon_{f} E_{f}}{D}
$$

The increased axial load carrying capacity of a strengthened column can be expressed as:

$$
P_{n}=k_{e} \varphi\left[0.85 \psi_{f} f_{c c}^{\prime}\left(A_{g}-A_{s t}\right)+f_{y} A_{s t}\right]
$$

Where $k_{e}=0.85$ for spiral reinforced columns and $k_{e}=0.80$ for tie reinforced columns; $\mathrm{P}_{\mathrm{n}}$ is the nominal axial load carrying capacity, $\varphi=0.75$ is the strength reduction factor; $\psi_{f}=0.95$ is the additional reduction coefficient for FRP wrapped columns, $A_{s t}=1.0$ is the longitudinal steel area; $A_{g}$ is the concrete total area and $f_{y}$ is the steel yield strength.

The Equation (6) only considers the axial increase in strength. For retrofitting in seismic areas, ACI 440 suggests using Mander et al. (1988) model for confined strain, $\varepsilon_{c c}$,

$$
\varepsilon_{c c}=\frac{1.71\left[5 f_{c c}^{\prime}-4 f_{c o}^{\prime}\right]}{E_{c}}
$$

Where $E_{C}$ is the modulus of elasticity of concrete. ACI 440 suggests that the design should be developed to have sufficient strain capacity associated to the desired displacement demands.

For each damage state, from DS-1 to DS-5, there is a deformation range for the transverse and longitudinal reinforcements (Table 2). Each deformation value can be associated with the axial capacity of the column through a sectional analysis of the 
element. The axial capacity for a certain level of deformation can be compared to the theoretical original capacity of the column prior to the damage, which can be determined using the following expression proposed by the ACI 318 (2008):

$$
P_{n}=0.80 \varphi\left[0.85\left(f_{c}^{\prime} A_{g}+f_{c c s}^{\prime} A_{c c}\right)+f_{y} A_{s}\right] .
$$

Where $P_{n}$ is the axial capacity of the column, $\varphi$ is the reduction factor of the transverse reinforcement, which is equal to 0.75 for closed stirrups, $A_{g}$ is the net area or total area of de column section, $A_{c c}$ is the confined area by the transverse reinforcement, $f_{y}$ is the yielding stress of the longitudinal steel, $A_{s}$ is the area of the longitudinal reinforcement and $f_{c c s}^{\prime}$ is the stress of the confined concrete produced by the transverse steel stirrups and can be determined with the expression of Richart et at. (1928), which is:

$$
f_{c c s}^{\prime}=f_{c}^{\prime}+4.1 f_{l} .
$$

where $f_{l}$ is the confinement pressure that results from the transverse reinforcement,

$$
f_{l}=\frac{2 A_{h} f_{s y}}{d s} .
$$

$A_{h}$ is the stirrups cross section area, $f_{s y}$ is the yielding stress of the transverse reinforcement, $d$ is the diameter of the column that is confined by the stirrups, which is equal to the diameter of the thick section, $D$, minus the double product of the concrete cover, $c c$, minus the double product of the stirrups diameter, $d h$. The spacing of stirrups is represented by $s$. The loss of axial capacity for each damage state is just the calculated theoretical axial capacity with equation (8) minus the axial capacity that the column would have for the deformation level at the corresponding damage, which is obtained from a sectional analysis.

With the loss of column axial capacity for a certain damage state, the thickness of the FRP band confinement necessary to restore the initial compression capacity of the column is obtained. The confinement effect of the FRP must be added to the equation to calculate the axial capacity of the column, so that the following equation is obtained:

$$
P_{n}=0.80 \varphi\left[0.85\left(f_{c}^{\prime} A_{g}+f_{c c s}^{\prime} A_{c c}+f_{c c}^{\prime} A_{g}\right)\right] .
$$

The effect of the longitudinal reinforcement, $f_{y} A_{s}$, is not taken into consideration because of the steel yielding at the deformations of the DS-1 damage state. Assessed the loss of axial load capacity for columns, the necessary FRP thickness can be calculated. The confinement stress of the concrete due to the FRP is determined with the following equation:

$$
f_{c c}^{\prime}=\frac{P_{i n i}-P_{d a m}}{(0.8 \varphi) 0.85 A_{g}} .
$$

where $P_{i n i}$ is the initial theoretical load capacity of the column and $P_{d a m}$ is the axial load capacity of the element for the damage state and it is obtained from a sectional analysis of the element. The thickness of the FRP band is calculated with following equation:

$$
t_{f}=\frac{D \rho_{f}}{4} .
$$

where,

$$
\rho_{f}=\frac{2 f_{l}}{k_{s} \varepsilon_{f} E_{f}} .
$$

In order to use equation 14 , it is necessary to know the value of $f_{l}$, which can be determined for comparison purposes, with any of the confinement stress models as function of $f_{l}$. Equation (13) can be written as follows: 


$$
t_{f}=\frac{D}{2} \frac{f_{l}}{k_{s} \varepsilon_{f} E_{f}} .
$$

\section{Caltrans memo 20.4 recommendations (2000)}

The Caltrans Memo 20-4 (2000) is specifically aimed at preventing flexure failure, and recommends the use of target confining stress, $f_{l}=2068 \mathrm{kPa}$ and radial dilating strain $\varepsilon_{c c}=0.004$ inside the plastic hinge zone. These limiting values were determined experimentally at a corresponding displacement ductility, $\mu=6.0$. For regions outside the plastic hinge zone, it is recommended to consider $f_{l}=1034 \mathrm{kPa}$ and $\varepsilon_{c c}=0.004$. The FRP thickness can be calculated using the following equation, which was derived from equilibrium:

$$
2 t_{f} E_{f} \varepsilon_{c c}=f_{l} D
$$

Then,

$$
t_{f}=\frac{f_{l} D}{2(0.90) E_{f} \varepsilon_{c c}} .
$$

Where $E_{f}$ is the elastic module of FRP and a reduction safety factor of 0.90 is added. This approach is exclusively based on target confinement pressure and does not specifically account for various possible failure modes.

It is worth to mention that previous recommendations are valid for non slender columns. Hence, second order effects were neglected.

\section{Example 1}

In this section the expressions proposed by the ACI 440.2R-02 and the Caltrans Memo 20-4 (2000) are applied to calculate the FRP thickness and to assess the axial capacity of a circular column with: diameter $D=305 \mathrm{~mm}$, height of $2438 \mathrm{~mm}$, concrete cover of $c c=19 \mathrm{~mm}$, unconfined concrete stress $f_{c}^{\prime}=34.45 \mathrm{MPa}$, and an elastic module of $E_{c}=27.58 \mathrm{MPa}$. The column has an FRP casing with the following properties: Elastic modulus of $E_{f}=59.36 \mathrm{MPa}$ and tensile strength of $f_{f}=752 \mathrm{MPa}$. The ultimate deformation of the FRP is:

$$
\varepsilon_{f u}=\frac{f_{f}}{E_{f}}=0.01266 \mathrm{~mm} .
$$

The longitudinal reinforcement consists of 16 bars number 3, each with an area of $71 \mathrm{~mm}^{2}$ for a total area of $A_{s}=1135 \mathrm{~mm}^{2}$; stirrups with a diameter of $d_{h}=4.92 \mathrm{~mm}$, an area of $A_{h}=19 \mathrm{~mm}^{2}$ spaced at $s=32 \mathrm{~mm}$. The yield stress of the steel is of $f_{y h}=420 M P a$.

The column of this example was experimentally tested and repaired by Vossoghi and Saiidi (2008), who used the expression of the Caltrans Memo 20-4 (2000) for repairing purposes and concluded that the design thickness of 2.03mm indeed restored the axial stress capacity of the damaged column and $87 \%$ of the column stiffness was restored.

The confinement pressure provided by the stirrups is the following:

$$
f_{h} \approx f_{l}=1.9405 \mathrm{MPa} .
$$
3).

The stress of confined concrete by the hoop steel $f_{c c s}^{\prime}$ can be calculated with one of the equations previously mentioned (Table

The effective axial load of the column, $P_{d a m}$, for the deformation state at the considered damage, is obtained from a sectional analysis of the column, for each damage level of the average deformation (Table 2). The deformation of the longitudinal steel for the damage state DS-4 is $0.0348 \mathrm{~mm} / \mathrm{m}$; a sectional analysis of the column [Response (2000)] showed that the resisting load for such deformation is of $173.03 \mathrm{kN}$.

Knowing the resistance of the damaged column, the necessary FRP thickness to restore its axial load capacity is determined. First, the value of the stress $f_{c c}^{\prime}$ is calculated and then, with the stress and deformation relationship, the confinement stress $f_{l}$ of the 
concrete due to the FRP is determined. Several expressions proposed by different authors can be used (Table 3), considering that the unconfined concrete stress is $f_{c o}^{\prime} \approx f_{c}^{\prime}$. The following expression [Karbhari (2005)] is used for comparison purposes.

$$
\frac{t_{f}}{2}=\frac{D f_{l}}{4 k_{s} \varepsilon_{f} E_{f}} .
$$

where $k_{s}=1.0$ (circular column); $\varepsilon_{f}$ is defined as the lower value of 0.0004 or $0.75 \varepsilon_{f u}$, where $\varepsilon_{f u}$ is the ultimate FRP deformation, $\varepsilon_{f u}=0.01266 \mathrm{~mm}$; i.e. $\varepsilon_{f}=0.0004$; equation (17) is applied to calculate the confinement thickness, considering $\varepsilon_{c c}=0.004$.

Table 5 presents the required FRP thickness for a damage state DS-4, to restore the axial column capacity obtained with the constitutive models proposed by several authors (Table 3). The thickness was computed with the expressions (19) and (20), for comparison purposes only. Youssef et al. (2007) equation conducts to the largest value, while the smallest one is obtained with the Bisby et al. (2005) expression. The confinement thickness obtained with the expressions (17) and (20) are in all cases different.

The results obtained with the equations suggested by the remaining authors provide more conservative values of the FRP thickness bands. Equation (20) results are in the range of 4.9 to $10.1 \mathrm{~mm}$, while equation (17) results are in the range of 5.4 to $11.2 \mathrm{~mm}$.

Considering that the expressions suggested by Mander et al. (1988) are widely recommended by most design codes, it can be deducted that the expressions proposed by other authors can be conservative, such is the case of Thériaul and Neale (2000), Lam and Teng (2002), and Wu et al. (2003).

Table 5. Values of the FRP thickness using the equations of different authors

\begin{tabular}{|c|c|c|c|c|c|c|c|}
\hline \multirow{2}{*}{ Author } & \multirow{2}{*}{$f_{c c s}^{\prime}$} & \multirow{2}{*}{$P_{i n i}$} & \multirow{2}{*}{$f_{c c}^{\prime}$} & \multirow{2}{*}{$f_{c c a}^{\prime}$} & \multirow{2}{*}{$f_{l}$} & \multicolumn{2}{|c|}{$t_{f}(\mathbf{m m})$} \\
\hline & & & & & & (20) & (17) \\
\hline Richart et al. (1928) & 42.406 & 2693.246 & 67.555 & 67.555 & 8.074 & 5.2 & 5.8 \\
\hline Mander et al. (1988) & 46.333 & 2797.272 & 70.347 & 70.347 & 7.582 & 4.9 & 5.4 \\
\hline Cusson and Paultre (1995) & 44.109 & 2738.346 & 68.766 & 68.766 & 11.870 & 7.6 & 8.5 \\
\hline Karbhari and Gao (1997) & 40.373 & 2639.390 & 66.110 & 66.110 & 13.325 & 8.6 & 9.5 \\
\hline Miyauchi et al. (1997) & 41.213 & 2661.633 & 66.707 & 66.707 & 9.256 & 5.9 & 6.6 \\
\hline Pilakoutas and Mortazavi (1997) & 43.608 & 2725.071 & 68.409 & 68.409 & 11.861 & 7.6 & 8.5 \\
\hline Kono et al. (1998) & 38.274 & 2583.786 & 64.618 & 64.409 & 15.203 & 9.8 & 10.8 \\
\hline Samaan et al. (1998) & 43.993 & 2735.286 & 68.683 & 68.683 & 12.035 & 7.7 & 8.6 \\
\hline Spoelstra and Monti (1999) & 31.419 & 2402.195 & 59.744 & 59.744 & 9.010 & 5.8 & 6.4 \\
\hline Toutanji (1999) & 44.906 & 2759.473 & 69.333 & 69.333 & 8.007 & 5.1 & 5.7 \\
\hline Saafi et al. (1999) & 41.214 & 2661.676 & 66.708 & 66.708 & 12.461 & 8.0 & 8.9 \\
\hline Thériaul and Neale (2000) & 38.331 & 2585.300 & 64.658 & 64.658 & 15.104 & 9.7 & 10.8 \\
\hline Lam and Teng (2002) & 38.331 & 2585.300 & 64.658 & 64.658 & 15.104 & 9.7 & 10.8 \\
\hline \multirow{3}{*}{ Wu et al. (2003) } & 38.331 & 2585.300 & 64.658 & 64.658 & 15.104 & 9.7 & 10.8 \\
\hline & 40.272 & 2636.703 & 66.038 & 66.038 & 10.529 & 6.8 & 7.5 \\
\hline & 39.301 & 2611.001 & 65.348 & 65.348 & 12.359 & 7.9 & 8.8 \\
\hline \multirow{3}{*}{ Bisby et al. (2005) } & 39.156 & 2607.146 & 65.245 & 65.245 & 12.699 & 8.2 & 9.1 \\
\hline & 40.007 & 2629.705 & 65.850 & 65.850 & 12.985 & 8.3 & 9.3 \\
\hline & 250.109 & 8195.178 & 215.212 & 215.212 & 1.573 & 1.0 & 1.1 \\
\hline Guralnick and Gunawan (2006) & 41.609 & 2672.130 & 66.988 & 66.989 & 11.645 & 7.5 & 8.3 \\
\hline Youssef et al. (2007) & 36.577 & 2538.839 & 63.411 & 63.411 & 15.673 & 10.1 & 11.2 \\
\hline \multirow{2}{*}{ Girgin (2009) } & 42.090 & 2684.869 & 67.330 & 67.330 & 12.515 & 8.0 & 8.9 \\
\hline & 39.634 & 2619.808 & 65.584 & 65.584 & 13.048 & 8.4 & 9.3 \\
\hline
\end{tabular}




\section{Seismic Reinforcement}

The approach proposed by Seible et al. (1997) and Karbhari (2005) differs from most of the aforementioned documents because it considers each failure mode separately and calculates a design thickness associated with each of the failure modes.

(i) Required thickness to prevent shear failure is calculated as follows:

$$
t_{j}=\frac{\frac{V_{0}}{\varphi_{v}}-\left(V_{c}+V_{s}+V_{p}\right)}{0.004\left(\frac{\pi}{2}\right) E_{f} D} .
$$

where $V_{0}$ is the column shear demand based on full flexural over-strength at the potential plastic hinge region, $\varphi_{v}=0.85$ is the shear capacity reduction factor, $V_{c}$ is the shear capacity contribution from concrete, $V_{s}$ is the shear capacity contribution from horizontal steel reinforcement and $V_{p}$ is the shear capacity contribution from axial load.

The shear demand, $V_{0}$, is calculated from the as built moment capacity, $M_{y i}$; Therefore, the shear demand is expressed as:

$$
V_{0}=\frac{1.5 M_{y i}}{H}
$$

where $H$ is the height of the column. The shear concrete contribution can be calculated with:

$$
V_{c}=k \sqrt{f_{c o}^{\prime}} A_{e} .
$$

In this equation, $k=0.50$ inside the plastic hinge and $k=3.0$ outside of it, and $A_{e}$ is the effective area, which can be considered as the $80 \%$ of the column gross area. However, in damaged columns the concrete contribution should be neglected, since the loose of aggregate interlock can be presented.

The shear contribution from the steel hoop reinforcement is calculated from,

$$
V_{s}=\frac{\pi}{2} \frac{A_{h} f_{y} D^{\prime} \cot \theta}{s}
$$

where $A_{h}$ is the area of hoop steel reinforcement and $\theta$ is the angle of the shear crack, which can conservatively be assumed as $45^{\circ}, s$ is the spacing between steel hoop and $D^{\prime}$ is the effective diameter, which is:

$$
D^{\prime}=D-2 c c-2 d_{h} .
$$

where, $D$, is the overall diameter, $c c$, is the concrete cover and $d_{h}$ is the diameter of the steel hoop bar. The shear contribution from the axial load is determined by:

$$
V_{p}=\frac{P(D-c)}{H}
$$

where $P$ is the applied axial load and $c$ is the neutral axis depth. The required thickness is applied over the shear reinforcement length, $L_{v}$, from either column ends, where $L_{v}$ is equal to 1.5 times the diameter of the column, $D$.

(ii) For the flexural hinge failure mode

The thickness in the flexural hinge region is calculated as follows: 


$$
t_{j}=0.09 \frac{D\left(\varepsilon_{c u}-0.004\right) f_{c c}^{\prime}}{\varphi_{f} f_{f} \varepsilon_{f}} .
$$

where $\varphi_{\mathrm{f}}=0.90$ is the flexural capacity reduction factor, conservatively it is assumed that $\mathrm{f}_{\mathrm{cc}}^{\prime}=1.5 \mathrm{f}_{\mathrm{co}}^{\prime}$ and $\varepsilon_{\mathrm{cu}}$ is the ultimate concrete strain that depends on the level of confinement, and is calculated as:

$$
\varepsilon_{c u}=0.004+\frac{2.8 \rho_{j} f_{f} \varepsilon_{f}}{f_{c c}^{\prime}} .
$$

where $\rho_{j}$ is the volumetric jacket reinforcement ratio; and $\varepsilon_{\mathrm{cu}}$ can be obtained from:

$$
\varepsilon_{c u}=\Phi_{u} c_{u}
$$

$c_{u}$ is the neutral axis depth and $\Phi_{u}$ is the ultimate section curvature and it can be obtained from the ductility factor equation:

$$
\mu_{\Delta}=1+3 \frac{L_{p}}{L}\left(\frac{\Phi_{u}}{\Phi_{y}}-1\right)\left(1-0.5 \frac{L_{p}}{L}\right) .
$$

where $\Phi_{y}$ is the section yield curvature and $L_{p}$ is the plastic hinge length, determined from:

$$
L_{p}=0.08 L+0.022 f_{y} d_{b} .
$$

The thickness required for the flexural reinforcement jacket is applied over the flexural plastic hinge region, where $L_{c 1}$ is the primary flexural hinge region, equal to the greater value of $0.5 D$ or $L / 8 ; L_{c 2}$ is the secondary flexural hinge region and is equal to the greater value of $0.5 D$ or $L / 8$. The secondary flexural hinge region has $t / 2$ thickness.

(iii) The lap slice failure mode is prevented through applying a FRP thickness in the lap splice region of:

$$
t_{j}=500 \frac{D\left(f_{l}-f_{h}\right)}{E_{f}} .
$$

where $f_{h}$ is the horizontal stress provided by the existing hoop reinforcement at a strain of $10 \%$ and it is calculated with the equation (33),

$$
f_{h}=\frac{0.002 A_{h} E_{s}}{s D} .
$$

and $f_{l}$ is the lateral clamping pressure, defined as,

$$
f_{l}=\frac{A_{s} f_{y}}{\left[\frac{p}{2 n}+2\left(d_{b}+c c\right)\right] L_{s}} .
$$

where $p$ is the perimeter line in the column cross section along the lap-spliced bar locations, $n$ is the number of spliced bars along $p ; A_{s}$ is the area of one main column reinforcing bar, $c c$ is the concrete cover to the main column reinforcement and $d_{b}$ is the diameter of the main column reinforcement bars. The lap splice reinforcement length, $L_{s}$, must be greater than the lap length itself. 


\section{Example 2}

In Seible et al. (1995) a column that is deficient in bending is reported. It had a limited development length and it was reinforced using FRP bands with a modulus of elasticity, $E_{f}=124.1 \mathrm{GPa}$ and ultimate stress of $f_{f}=1.31 \mathrm{GPa}$; the ultimate strain is:

$$
\varepsilon_{f}=\frac{f_{f}}{E_{f}}=\frac{1.31 G P a}{124.1 G P a}=0.0106 \approx 1.10 \%
$$

Table 6 shows the columns loads and properties.

Table 6. Properties of the column with bending resistance deficiency [Seible et al. (1995)]

\begin{tabular}{|c|c|c|}
\hline \multirow{4}{*}{ Column section properties } & Column height, $\mathrm{H}$ & $3.658 \mathrm{~m}$ \\
\hline & Column diameter, $\mathrm{D}$ & $0.61 \mathrm{~m}$ \\
\hline & Concrete cover, cc & $19.05 \mathrm{~mm}$ \\
\hline & Concrete strength, $f_{c}^{\prime}$ & $34.45 \mathrm{MPa}$ \\
\hline \multirow{3}{*}{$\begin{array}{l}\text { Longitudinal reinforcement } \\
\text { (grade 40) }\end{array}$} & Bars diameter, $d_{b}$ ( 26 total) & $19 \mathrm{~mm}$ \\
\hline & Bar area, $A_{s}$ & $284 \mathrm{~mm} 2$ \\
\hline & Yield strength $f_{y}$ & $303.4 \mathrm{MPa}$ \\
\hline \multirow{3}{*}{$\begin{array}{c}\text { Transverse } \\
\text { reinforcement (grade 40) }\end{array}$} & Bar diameter, $d_{h}$ & $6.35 \mathrm{~mm}$ \\
\hline & Bar area, $A_{h}$ & $31.7 \mathrm{~mm} 2$ \\
\hline & Spacing, $s$ & $127 \mathrm{~mm}$ \\
\hline \multirow{4}{*}{ Column load properties } & Axial load, $P$ & $1800 \mathrm{kN}$ \\
\hline & Moment capacity, $M_{y i}$ & $518.6 \mathrm{kNm}$ \\
\hline & Yield curvature, $\varphi_{y}$ & $0.0081961 / \mathrm{m}$ \\
\hline & Neutral axis, $c_{u}$ & $136.4 \mathrm{~mm}$ \\
\hline
\end{tabular}

The ACI 440.2R (2002) incorporates in the seismic reinforcement process the constitutive model as function of stresses, $f_{c c}^{\prime}$, as well as the model in function of the strain, $\varepsilon_{c c}$. The suggested process by ACI 440.2R (2002) and the different models of confinement suggested by several authors (Tables 3 and 4) are used. It is assumed that a ductility of $\mu_{\Delta}=10$ is required, as it is usual in reinforced concrete columns for bridges. The design basic values are shown in Table 7.

Table 7. Design values of example 2

\begin{tabular}{|c|c|c|c|c|c|c|c|}
\hline \multirow{2}{*}{ Column } & \multirow{2}{*}{$\mathrm{Lp}(\mathrm{mm})$} & \multicolumn{2}{|c|}{$\mu_{\Phi}$} & \multirow{2}{*}{\begin{tabular}{c}
\multirow{2}{*}{$c_{u}$} \\
$\mu_{u}$
\end{tabular}} & \multicolumn{2}{c|}{$\varepsilon_{c c}(\mathrm{~mm})$} \\
\cline { 3 - 4 } \cline { 7 - 8 } & & $\mu_{\Delta}=8$ & $\mu_{\Delta}=10$ & $(1 / \mathrm{m})$ & $(\mathrm{mm})$ & $\mu_{\Delta}=8$ & $\mu_{\Delta}=10$ \\
\hline Example 2 & 273.14 & 17.89 & 22.71 & 0.008196 & 136.4 & 0.01999 & 0.0254 \\
\hline
\end{tabular}

By applying the shear design procedure suggested by Seible et al. (1995) the design values of Table 8 were obtained. As it can be observed, the column does not present shear stress problems.

Table 8. Design values by shears stress

\begin{tabular}{|c|c|c|c|c|c|c|c|}
\hline Column & $M_{y i}(\mathrm{kN} \mathrm{m})$ & $V_{0}(\mathrm{kN})$ & $P(\mathrm{kN})$ & $\begin{array}{c}D^{\prime} \\
(\mathrm{mm})\end{array}$ & $\begin{array}{c}V_{s} \\
(\mathrm{kN})\end{array}$ & $\begin{array}{c}V_{p} \\
(\mathrm{kN})\end{array}$ & $\begin{array}{c}t_{j} \\
(\mathrm{~mm})\end{array}$ \\
\hline Example 2 & 518.6 & 216.66 & 1800.0 & 565.55 & 67.276 & 233.04 & .0001 \\
\hline
\end{tabular}

For bending reinforcement, the FRP thickness in the zone of plastic articulation is calculated with: 


$$
t_{j}=0.09 \frac{D\left(\varepsilon_{c u}-0.004\right) f_{c c}^{\prime}}{\varphi_{f} f_{f} \varepsilon_{f}} .
$$

where $\varphi_{f}=0.90$ is the resistance reduction factor. Considering $f_{c c}^{\prime}=1.5 f_{c o}^{\prime}, f_{f}=1.30 \mathrm{GPa}$ and the ultimate strain of $\varepsilon_{f}=0.0106$, the confinement thicknesses obtained are summarized in Table 9.

Table 9. Design of FRP thickness for bending

\begin{tabular}{|c|c|c|c|c|c|c|}
\hline \multirow{2}{*}{ Column } & \multicolumn{2}{|c|}{$\varepsilon_{c u}(\mathrm{~mm})$} & \multirow{2}{*}{$\begin{array}{c}t_{j} \\
(\mathrm{~mm})\end{array}$} & \multirow{2}{*}{$\begin{array}{l}t_{j} / 2 \\
(\mathrm{~mm})\end{array}$} & \multirow{2}{*}{$\begin{array}{c}t_{j} \\
(\mathrm{~mm})\end{array}$} & \multirow{2}{*}{$\begin{array}{l}t_{j} / 2 \\
(\mathrm{~mm})\end{array}$} \\
\hline & $\mu_{\Delta}=8$ & $\mu_{\Delta}=10$ & & & & \\
\hline Example 2 & 0.01999 & 0.0254 & 9.6 & 4.8 & 12.9 & 6.4 \\
\hline
\end{tabular}

Determining the value of $\varepsilon_{c c}$ (table 7), the required confinement stress $f_{c c}^{\prime}$ or $f_{l}$ is calculated (Table 3 ), that is,

$$
f_{c c}^{\prime}=\frac{\frac{\varepsilon_{c c} E_{c}}{1.71}+4 f_{c}^{\prime}}{5}
$$

$f_{l}$ depends on the stresses and the FRP thickness is calculated with the following equation,

$$
t_{f}=\frac{D}{2} \frac{f_{l}}{k_{s} \varepsilon_{f} E_{f}} .
$$

Table 10 shows the required thickness of the confinement obtained for a ductility capacity of 10 with the models suggested by some of the previously mentioned authors. The confinement thickness must be compared with the value defined with the ACI methodology of $12.9 \mathrm{~mm}$, reported on Table 9 .

It can be observed that a large dispersion exists in the results obtained for the FRP thickness by using the strain equations of different authors (table 10). The FRP thickness values for a deformation of $\varepsilon=0.0173 \mathrm{~mm} / \mathrm{m}$, varied in the range of 4.7 to $18.7 \mathrm{~mm}$ and for a deformation of $\varepsilon=0.0254 \mathrm{~mm} / \mathrm{m}$ the thickness values of the FRP bands are within a range of 6 to $29 \mathrm{~mm}$. The third column of Table 10 shows the percentage of the relative error, considering as the correct one, the thickness obtained with the

\begin{tabular}{|c|c|c|c|}
\hline \multirow{2}{*}{ Author } & $\varepsilon_{c c}=0.0173$ & $\varepsilon_{c c}=0.0254$ & \multirow{2}{*}{$\Delta(\%)$} \\
\hline & \multicolumn{2}{|c|}{$t_{f}(\mathrm{~mm})$} & \\
\hline Richart et al. (1928) & 7.9 & 12 & -7 \\
\hline Mander et al. (1988) & 8.4 & 18 & 47 \\
\hline Cusson and Paultre (1995) & 4.7 & 6 & -53 \\
\hline Kono et al. (1998) & 16.8 & 26 & 102 \\
\hline Toutanji (1999) & 13.7 & 23 & 81 \\
\hline Saafi et al. (1999) & 18.7 & 24 & 86 \\
\hline Lam and Teng (2002) & 9.4 & 15 & 16 \\
\hline \multirow{3}{*}{ Bisby et al. (2005) } & 13.5 & 21 & 63 \\
\hline & 18.7 & 29 & 125 \\
\hline & 6.0 & 9 & -30 \\
\hline Youssef et al. (2007) & 11.1 & 18 & 40 \\
\hline
\end{tabular}
procedure suggested by Seible et al. (1997).

Table 10. FRP thickness of confinement for $\mu_{\Delta}=10$ 


\section{Conclusions}

The structural retrofit and repair using Polymer Fibers (FRP, Fiber Reinforced Polymers) has increased in recent years. For the case of columns that have suffered some type of damage during an earthquake occurrence, the application of the FRP jacket technique is a rapid and efficient alternative. This study presents the possible application of different FRP jackets for repairing the seismic damage of circular columns. First, it is determined the damage state of a column according to the Repair of Concrete Structures Manual [ACI, BRE, Concrete Society and ICRI (2001)]. After the damage state has been specified, the possibility of performing its repair by means of FRP jacket is determined. When evaluating different expressions for calculation the FRP thickness of confinement, it was found that a great dispersion exists in spite of the analytical and experimental background of each author proposals. In a practical application, it is therefore difficult to determine the best model to be used.

\section{Aknowledgments}

We are grateful to Universidad Michoacana de San Nicolás de Hidalgo for supporting this study.

\section{References}

ACI-440.2R Committee, 2002. Guide for the design and construction of externally bonded FRP systems for strengthening concrete structures. $A C I$, Detroit.

ACI 318-08, 2008. Building code requirements for structural concrete. ACI, Farmington Hill, MI.

ACI, BRE, Concrete Society and ICRI, 2001. Concrete repair manual. ACI, Farmington Hills, MI.

Bentz, E., 2001. Response 2000. Version 1.1.

Concrete Society, 2004. Design guidance for strengthening concrete structures using fiber composite material. Technical Report, No 55, Crowthorne, UK.

Cusson, D. and Paultre, P., 1995. Stress-strain model for confined high-strength concrete. J. Struct. Eng., Vol. 121, No. 3, pp. 468477.

Fradis, M. N. and Khalili, H. H., 1982. FRP encased concrete as a structural material, Mag. of Concrete Res., Vol. 34, No. 131, pp. 191-202.

International Federation for Structural Concrete, FIB created form CEB and FIP, 2003. Seismic assessment and retrofit of reinforced concrete buildings. State of art report prepared by Task Group 7.1, ISBN 2-88394-064-9.

Karbhari, V. M., and Gao, Y., 1997. Composite jacketed concrete under uniaxial compression-verification of simple design equations, J. Mater. Civ. Eng., Vol. 9, No. 4, pp. 185-193.

Karbhari V. M., 2005. Using Composites in Seismic Retrofit Applications, The Aerospace Corporation, El Segundo, California.

Lam, L. and Teng, J. G., 2002. FRP strengthened RC structures, West Sussex, England, John Wiley and Sons, Inc.

Lee, C., Bonacci, J. F., Thomas, M. D., Maalej, M., Khajehpour, S., Hearn, N., Pantazopoulou, S. and Sheikh, S., 2000. Accelerated corrosion and repair of reinforced concrete columns using carbon fiber reinforced polymer sheets, Can. J. Civ. Eng., Vol. 27, pp. 941-948.

Li, G., Kidane, S., Pang, S. S., Helms, J. E. and Stubblefied, M. A., 2003. Investigation into FRP repair RC columns, Comp. Struct., Vol. 62, pp. 83-89.

Ma, R. and Xiao, Y., 1999. Seismic retrofit and repair of circular bridge columns with advanced composite materials, Earth. Spect. Vol. 15, No. 4, pp. 747-764.

Mander, J. B., Prriestley, M. J. N., and Park, R. J. T., 1988. Theoretical stress-strain model for confined concrete, J. Struct. Eng., Vol. 114, No. 8, pp. 1804-1826.

Miyauchi, K., Nishibayashi, S., and Inoue, S., 1998. Estimation of strengthening effects with carbon fiber sheet for concrete columns, Proc., $3 d r$ Int. Symp. On Non Metallic (FRP) Reinforcement for Concrete Structures, Japan Concrete Institute, Vol. 1, pp. 217-224.

Pilakoutas K., and Mortazavi A., A., 1997. Ductility through external confinement of RC members with FRP, Non-metallic (FRP) reinforcement for concrete structures, Japan Concrete Institute, Tokyo, Vol. I, pp. 225-232.

Richart, F. E., Brandtzaeg, A. and Brown, R. L., 1928. A study of the failure of concrete under combined compressive stresses.

Saadatmanesh, H., Ehsani, M. R., and Jin, L., 1997. Repair of earthquake damage RC columns with FRP wraps, ACI Struct. J., Vol. 94, No. 2, pp. 206-211.

Saafi, M., Toutanji, H. A., and Zongjin, L., 1999. Behavior of concrete columns confined with fiber reinforced polymer tubes, $A C I$ Mater. J., Vol. 96, No. 4, pp. 500-509.

Samaan, M., Mirmiran, A., and Shahawy, M., 1998. Model of concrete confined by fiber composites, J. Struct. Engrg., Vol. 124, No. 9, pp. 1025-1031.

Seible, F. and Innamorato, D., 1995. Earthquake retrofit of bridge columns with continuous carbon fiber jackets, volume II, design guidelines, Advanced Composites Technology Transfer Consortium, Report No. ACTT-95/08. 
Seible, F., Preistley, M. J. N., Gegemier, G. A. and Innamorato, D., 1997. Seismic retrofit of RC columns with continuous carbon fiber jackets, J. Comp Constr., Vol. 1, No. 2, pp. 52-62.

Spoelstra, M. R., and Monti, G., 1999. FRP confined concrete model, J. Comps. Constr., Vol. 3, No. 3, pp. 143-150.

Tastani, S. P., Pantazopoulou, S. J., Zdoumba, D., Plakantaras, V. and Akritidis, E., 2006. Limitations of FRP jacketing in confining old-type reinforced concrete members in axial compression, J. Mater. Civ. Eng., Vol. 10, No. 1, pp. 52-57.

Teng J. G., Chen J. F., Smith S. T., and Lam L., 2002. FRP Strengthened RC Structures, John Wiley and Sons, LTD, ISBN 0-47148706-6.

Thériault M., Neale K. W., 2004. Fiber-Reinforced Polymer-Confined Circular Concrete Columns: Investigation of Size and Slenderness Effects, Journal of Composites for Construction, ASCE, July-August, Vol. 8. No. 4, pp. 323-331.

Toutanji, H., 1999. Stress-strain characteristics of concrete columns externally confined with advanced fiber composite sheet, $A C I$ Mater. J., Vol. 96, No. 3, pp. 397-404.

Vosooghi, A. and Saiid Saiid, M., 2008. Emergency repair of damage bridge columns using fiber reinforced polymer (FRP) materials, Progress report to Caltrans.

Xiao, Y., and $\mathrm{Wu}, \mathrm{H} ., 2000$. Compressive behavior of concrete confined by carbon fiber composite jackets, J. Mater. Civ. Eng., Vol. 12, No. 2, pp. 139-146.

Youssef, M. N., Feng, M. Q., Mosallam, A. S., 2007. Stress-strain model for concrete confined by FRP composites, Comp. Part B, Vol. 38, pp. 614-628.

\section{Biographical notes}

H. Hernández received his Bachelor degree in Civil Engineering in 1990. He worked for 6 years as a design engineer, designing various reinforced concrete structures. He received his Master of Science and Doctor of Philosophy degrees from the University of Mexico, UNAM, in 2002.

Hernández's research interests include but not limited to seismic analysis and design of highway bridges, laboratory testing of reinforced and prestressed concrete members. He is Researcher Level 1, in the SNI-CONACyT. Since 2004 he is professor at Universidad Michoacana de San Nicolas de Hidalgo, UMSNH, Civil Engineering School, Morelia, México.

J.M. Jara received his PhD form UNAM University in Mexico. He is currently Titular Professor of the Civil Engineering School at the University of Michoacan in Mexico. His research activity includes seismic hazard assessment, cost-benefit studies, use of passive control systems in structures and seismic behavior of bridges. Dr J.M. Jara has been principal investigator of several projects supported by the National Council for Science and Technology in Mexico. He has published papers in index international journals and in national and international conferences. He has written as co-author two books related to seismic engineering.

M. Jara is Professor of Civil Engineering at the Universidad Michoacana de San Nicolás de Hidalgo. He received his doctorate from the UPC-Barcelona Tech., Catalonia, Spain. Dr M. Jara has participated in research projects that have lead to changes in Mexican design codes and recommendations in the area of seismic engineering and seismic bridge engineering. He was named Member of the National System of Researchers in Mexico (SNI) in recognition of his research activities. The Universidad Autonoma Metropolitana and the Civil Engineering Association of Mexico (CICM) recognized him as a distinguished pregraduate. His research interests are on seismic engineering, particularly seismic bridge performance.

Received December 2010

Accepted June 2011

Final acceptance in revised form June 2011 